\title{
Milk fat depression in dairy ewes fed fish oil: Might differences in rumen biohydrogenation, fermentation, or bacterial community explain the individual variation?
}

\author{
P. Frutos, P. G. Toral, ${ }^{1}$ A. Belenguer, and G. Hervás \\ Instituto de Ganadería de Montaña (CSIC-Universidad de León), Finca Marzanas s/n, 24346 Grulleros, León, Spain
}

\begin{abstract}
Dairy ewes show large individual variation in the extent of diet-induced milk fat depression (MFD) but reasons behind this variability remain uncertain. Previous results offered no convincing support for these differences being related to relevant changes in the milk fatty acid (FA) profile, including potentially antilipogenic FA, or in the transcript abundance of candidate genes involved in mammary lipogenesis. Therefore, we hypothesized that alterations in the processes of rumen biohydrogenation and fermentation, as well as in the bacterial community structure, might account for individual variation in fish oil-induced MFD severity. To test this explanation, 15 ewes received a total mixed ration without lipid supplementation (control; $\mathrm{n}=5$ ) or supplemented with $20 \mathrm{~g}$ of fish oil/ $\mathrm{kg}$ of dry matter $[10$ animals divided into those showing a strong (RESPON+; $-25.4 \% ; \mathrm{n}=5$ ) or a mild (RESPON-; $-7.7 \% ; \mathrm{n}=5$ ) decrease in milk fat concentration] for 5 wk. Rumen fermentation parameters, biohydrogenation metabolites, and bacterial structure and diversity were analyzed in rumen samples collected before and after treatments. Although the fish oil supplementation increased the concentration of demonstrated or putative antilipogenic FA (e.g., cis-9 16:1, cis-11 18:1, or trans-10,cis-12 CLA), surprisingly, none of them differed significantly in relation to the extent of MFD (i.e., between RESPON - and RESPON+), and this was the case only for a few minor FA (e.g., cis-6+7 16:1 or 17:0 anteiso). Changes in total volatile FA, acetate, and propionate concentrations were associated with MFD severity, with higher decreases in more susceptible animals. Individual responses were not related to shifts in rumen bacterial structure but some terminal restriction fragments compatible with Clostridiales, Ruminococcaceae, Lachnospiraceae, and Succiniclasticum showed greater abundances in RESPON-, whereas some oth-
\end{abstract}

Received February 23, 2018.

Accepted March 20, 2018.

${ }^{1}$ Corresponding author: pablo.toral@csic.es ers that may correspond to Prevotella, Mogibacterium, and Quinella-related spp. were more abundant in RESPON+. Overall, the results suggest that individual variation in MFD severity in dairy ewes fed fish oil cannot be fully explained by differences in the processes of rumen biohydrogenation and fermentation or in the bacterial community, and further research would be necessary to elucidate the large variability in the responsiveness to MFD-inducing marine lipids.

Key words: acetate, fatty acid, marine lipid, ruminal microbiota, sheep

\section{INTRODUCTION}

Diet-induced milk fat depression (MFD) is commonly observed in sheep when they are fed marine lipid supplements to modulate milk fatty acid (FA) composition (e.g., Toral et al., 2016b; Frutos et al., 2017). However, dairy ewes, like dairy cows, show large individual variation in the extent of this condition (Reynolds et al., 2006; Weimer et al., 2010). For example, Toral et al. (2016b) observed up to 8-fold differences in milk fat decreases within a group of lactating sheep fed the same MFD-inducing diet. Yet, reasons behind this variability are uncertain.

Elucidating the cause of this different responsiveness might help to understand diet-induced MFD, which continues to be an active research area given the economic value of milk fat and associated losses (Palmquist and Jenkins, 2017). With that aim, we conducted an experiment (Frutos et al., 2017) with dairy ewes displaying either strong or just mild MFD when fed a diet containing $2 \%$ fish oil. Unexpectedly, results offered no convincing support for individual variations being linked to relevant changes in the milk FA profile, including potentially antilipogenic FA, or with the transcript abundance of candidate genes involved in mammary lipogenesis. Therefore, further research was necessary.

Bauman and Griinari (2001) postulated that MFD is related to active biohydrogenation (BH) intermediates that are produced under several feeding conditions 
that alter rumen function, and referred to this as the $\mathrm{BH}$ theory of MFD. The production of these intermediates is primarily due to the rumen microbiota, especially bacteria, with no or limited contribution of other groups such as protozoa or fungi (Lourenço et al., 2010; Enjalbert et al., 2017). Nonetheless, it is still uncertain which populations are actually involved in the process (Buccioni et al., 2012; Enjalbert et al., 2017; Pitta et al., 2018). Although most studies focused on the trans10,cis-12 18:2, whose role in marine lipid-induced MFD has been dismissed (Loor et al., 2005; Toral et al., 2012), other BH metabolites with potentially antilipogenic features have then been connected to mammary lipogenesis (Alves and Bessa, 2014; Kairenius et al., 2015; Toral et al., 2016b). For this reason, we speculated that some minor $\mathrm{BH}$ metabolites possibly associated with BH-induced MFD might be better detected in rumen fluid than in milk as changes occurring in the mammary gland would be excluded.

Furthermore, early theories attributed the reduction in milk fat to an acetate deficiency because this VFA is the main substrate for de novo synthesis of FA in dairy ruminants, but they were disregarded based on experiments infusing acetate to cows (see review by Bauman and Griinari, 2001). However, Urrutia and Harvatine (2017) have recently resumed research on the effect of acetate on mammary lipid synthesis and suggested that the subject would merit further investigation.

On this basis, this study was conducted to test the hypothesis that differences in the processes of rumen BH of UFA and fermentation, as well as in the bacterial community, would account for the individual variation in fish oil-induced MFD severity.

\section{MATERIALS AND METHODS}

All experimental procedures were approved and completed in accordance with European Union and Spanish regulations [R.D. 53/2013 (BOE, 2013), and Council Directive 2010/63/EU (EU, 2010)] for the protection of animals used for experimental purposes.

\section{Animals and Experimental Diets}

Details of the experimental design and methodology were described in Frutos et al. (2017). Briefly, we used 15 lactating Assaf ewes $(76.4 \pm 2.66 \mathrm{~kg}$ of BW; $48 \pm$ $1.4 \mathrm{DIM} ; 2.8 \pm 0.15 \mathrm{~kg}$ of milk/d; means $\pm \mathrm{SE}$ ) that were selected from a total of 27 animals randomly allocated to 1 of 2 diets: a TMR based on alfalfa hay and a concentrate (50:50) without lipid supplementation (control group; $\mathrm{n}=5$ ) or supplemented with $20 \mathrm{~g}$ of fish oil (Afampes 121 DHA; Afamsa, Mos, Spain) $/ \mathrm{kg}$ of diet DM to cause MFD (MFD group; $\mathrm{n}=22$ ). On average, experimental diets contained $138 \mathrm{~g}$ of starch, $180 \mathrm{~g}$ of CP, and $315 \mathrm{~g}$ of NDF $/ \mathrm{kg}$ of DM [see Frutos et al. (2017) for further details about chemical composition, ingredients, and FA profile]. All ewes were fed the control diet for a 21-d adaptation period and then both experimental diets for 36 more days. At the end of this latter period, 10 animals out of the 22 were selected and divided in those showing a strong MFD (RESPON+; $-25.4 \%$ decrease in milk fat concentration; $\mathrm{n}=5$ ) or a mild MFD (RESPON-; $-7.7 \%$ decrease in milk fat concentration; $\mathrm{n}=5)$.

\section{Measurements and Sampling Procedures}

At the end of the adaptation period and after $36 \mathrm{~d}$ on the experimental diets, ewes were given free access to the diets for $1 \mathrm{~h}$ after morning milking. Then, feeds were removed and $3 \mathrm{~h}$ later, samples of rumen fluid were collected from each animal (approximately 150 $\mathrm{mL}$ ) using an oral stomach probe (Ramos-Morales et al., 2014). Immediately after collection, the fluid was strained through a nylon membrane $(400 \mu \mathrm{m}$; Fisher Scientific S.L., Madrid, Spain); a 3-mL subsample was acidified with $3 \mathrm{~mL}$ of $0.2 \mathrm{M} \mathrm{HCl}$ for ammonia analysis, and further $0.8-\mathrm{mL}$ aliquots were deproteinized with $0.5 \mathrm{~mL}$ of $20 \mathrm{~g}$ of metaphosphoric acid/L and $4 \mathrm{~g}$ of crotonic acid/L in $0.5 \mathrm{M} \mathrm{HCl}$ for VFA determinations. These samples were stored at $-30^{\circ} \mathrm{C}$ until analysis. Further aliquots of ruminal fluid were collected (approximately $50 \mathrm{~mL}$ ), immediately frozen at $-80^{\circ} \mathrm{C}$, freeze-dried, and stored again at $-80^{\circ} \mathrm{C}$ until analyzed for FA composition and bacterial community.

\section{Laboratory Analysis}

Ruminal Fermentation Parameters. Ammonia concentration was determined by a colorimetric method (Reardon et al., 1966) and VFA by GC, using crotonic acid as an internal standard (Ottenstein and Bartley, 1971), both in centrifuged samples.

Ruminal Fatty Acid Composition. Fatty acid methyl esters of lipid in $200 \mathrm{mg}$ of freeze-dried rumen digesta samples were extracted twice using $4 \mathrm{~mL}$ of a mixture $(3: 2, \mathrm{vol} / \mathrm{vol})$ of hexane and isopropanol following the adjustment of digesta $\mathrm{pH}$ to 2 using $2 \mathrm{M}$ $\mathrm{HCl}$ (Shingfield et al., 2003), and adding cis-12 13:1 (10-1301-9, Larodan Fine Chemicals AB, Solna, Sweden) as an internal standard. Organic extracts were combined and dried under nitrogen at $50^{\circ} \mathrm{C}$. Lipid dissolved in $2 \mathrm{~mL}$ of hexane was converted to FAME using a sequential base-acid catalyzed transesterification procedure with freshly prepared $0.5 \mathrm{M}$ sodium methoxide 
in methanol for $5 \mathrm{~min}$ at $20^{\circ} \mathrm{C}$ followed by reaction with $1 \%$ (vol/vol) sulfuric acid in methanol at $50^{\circ} \mathrm{C}$ for 30 min (Toral et al., 2017). Methyl esters were separated and quantified using a gas chromatograph (Agilent 7890A GC System, Santa Clara, CA) equipped with a flame-ionization detector and a 100-m fused silica capillary column (0.25 mm i.d., 0.2- $\mu \mathrm{m}$ film thickness; CPSIL 88, CP7489, Varian Ibérica S.A., Madrid, Spain) and hydrogen as the carrier gas $(207 \mathrm{kPa}, 2.1 \mathrm{~mL} / \mathrm{min})$. Total FAME profile in a $2-\mu \mathrm{L}$ sample volume at a split ratio of 1:20 was determined using a temperature gradient program, and isomers of 18:1 were further resolved in a separate analysis under isothermal conditions at $170^{\circ} \mathrm{C}$ (Shingfield et al., 2003). Peaks were identified based on retention time comparisons with commercially available standards (Larodan Fine Chemicals AB, NuChek Prep, Elysian, MN; and Sigma-Aldrich, Madrid, Spain), cross referencing with chromatograms reported in the literature (e.g., Shingfield et al., 2003), and comparison with reference samples for which the FA composition was determined based on GC analysis of FAME and GC-MS analysis of corresponding 4,4-dimethyloxazoline derivatives (Toral et al., 2017).

Ruminal Bacterial Community. Freeze-dried rumen samples were thoroughly homogenized before DNA extraction, which was carried out following the protocol described by $\mathrm{Yu}$ and Morrison (2004), with the modification of a higher temperature $\left(95^{\circ} \mathrm{C}\right)$ to improve cell lysis. Duplicate DNA samples were combined and used as templates for terminal (T) RFLP analysis of bacterial 16S rRNA genes. This was performed using a universal bacteria specific primer pair set [6-carboxy-fluorescein (FAM)-labeled $27 \mathrm{f}=$ 5'-6-FAM-AGAGTTTGATCCTGGCTCAG-3'; and 1389r = 5'-ACGGGCGGTGTGTACAAG-3'; Hongoh et al., 2003]. The PCR products were purified and then digested with HhaI, HaeIII, and MspI in single-enzyme digestions. The labeled terminal restriction fragments (T-RF) were analyzed by capillary electrophoresis on an automatic sequence analyzer (MegaBace 500, GE Healthcare Life Sciences, Buckinghamshire, UK) and their lengths were determined with the size standard ET-550-R (GE Healthcare Life Sciences) using the GeneMarker Analysis software (SoftGenetics, State College, PA). To infer the potential bacterial composition, in silico restrictions for gut bacteria were obtained from the Ribosomal Database Project II website (http://rdp .cme.msu.edu/index.jsp). Data from T-RFLP (size, bp, and peak area for each T-RF) were analyzed as outlined by Abdo et al. (2006), and used to determine the relative abundance of each fragment and the diversity indices (number of T-RF or richness, Shannon-Wiener and Shannon evenness; Hill et al., 2003).

\section{Calculations and Statistical Analysis}

Statistical analyses were performed using the SAS software package (version 9.4, SAS Institute Inc., Cary, $\mathrm{NC}$ ). Ruminal fermentation parameters, BH metabolites, and bacterial diversity indices were analyzed by one-way analysis of covariance (ANCOVA) with a model that included the fixed effect of treatments (control, RESPON-, and RESPON+), and measurements at the end of the adaptation period as a covariate. Animals were nested within treatment. Previously defined orthogonal contrasts were used to confirm the effects of fish oil supplementation [i.e., control vs. MFD (RESPON+ and RESPON-)], as well as to examine differences in the response within ewes with diet-induced MFD (i.e., RESPON+ vs. RESPON-). For relative abundances of T-RF, because most of them did not satisfy the assumptions of normality, a Blom rank-based nonparametric ANCOVA (with orthogonal contrast) was applied. Differences were declared significant at $P$ $<0.05$ and considered a trend toward significance at $0.05 \leq P<0.10$. Least squares means are reported.

The relationship between ruminal fermentation parameters, $\mathrm{BH}$ metabolites, and T-RFLP data at the end of the adaptation period and after $36 \mathrm{~d}$ on treatments was assessed through a principal component analysis (PCA) using the R-project software (version 3.2.3; http://www.r-project.org).

\section{RESULTS}

\section{Rumen Fatty Acid Profile}

Inclusion of fish oil in the diet altered the concentration of most FA identified in ruminal digesta and increased total FA content by $36 \%(P<0.05$; Table 1 and Supplemental Table S1; https://doi.org/10.3168/ jds.2018-14632). Changes in FA profile were characterized by strong decreases in 18:0 (on average, $-85 \%$ compared with the control; $P<0.001)$ and large increases in trans-11 18:1 $(P<0.001)$, which was the most abundant FA in the rumen of supplemented ewes $(\approx 21 \%$ of total FA). However, the few significant differences between RESPON - and RESPON + were limited to minor FA. Specifically, dietary fish oil enhanced the concentration of cis-6+7 16:1, cis-9,trans-11 CLA, cis$1522: 1$, and 22:4n-3 to a greater extent in ewes showing severe MFD $(P<0.10)$. Concentrations of 15:0 iso, 17:0 anteiso, cis-11,cis-14 18:2, and trans-9,trans12,cis-15 + cis-9,cis-12,trans-15 18:3 also tended to be greater in RESPON+ than in RESPON- $(P<0.10)$, but none of their values differed significantly from the control. Increases to lipid supplementation in most 
demonstrated or putative antilipogenic FA (e.g., cis9 16:1, 10-oxo-18:0, cis-11 18:1, trans-10,cis-12 CLA, trans-10, cis-15 18:2, which coeluted with trans-11, cis-15 18:2, or 22:6n-3) were not related to differences in MFD intensity (i.e., between RESPON - and RESPON+; $P$ $>0.10)$. Numerical variation in trans-10 18:1 did not reach the required level of significance $(P=0.16)$, and trans-9,cis-11 CLA could not be detected in digesta.

Dietary fish oil decreased the ruminal concentration of 18:2n-6 and 18:3n-3 $(P<0.001)$ and promoted the accumulation of most 18-carbon $\mathrm{BH}$ intermediates, including some trans-18:1, cis-18:1, and trans-18:2 isomers $(P<0.05)$. Some minor metabolites of ruminal $\mathrm{BH}$ and hydration were only detected in ewes receiving the marine lipid (e.g., cis-12,cis-15 + cis-12,cis-16 18:2). On the other hand, the proportion of few 18:1 and 18:2 isomers with at least one double bond at positions $\Delta 13$ to $\Delta 16$ (e.g., cis-16 18:1 and trans-11,trans-13 CLA) was lower in supplemented ewes $(P<0.10)$. None of these changes showed significant differences between RESPON- and RESPON+.

Consequences of fish oil feeding on ruminal odd- and branched-chain FA concentrations included increases (17:0 and 17:0 iso), no effects (15:0 and trans $-5+6+7$ 15:1), and decreases (15:0 anteiso and 16:0 iso). Only 15:0 iso and 17:0 anteiso variations were associated with MFD extent. Most FA present in the marine lipid (such as 14:0, cis-9 16:1, and 22:6n-3) and their unsaturated $\mathrm{BH}$ metabolites were more abundant $(P<$ 0.05 ) or could only be detected in the digesta of MFD sheep. However, 20:0 and 22:0 were reduced in both RESPON- and RESPON+, but without differences between them $(P>0.10)$.

\section{Rumen Fermentation Characteristics}

As shown in Table 2, feeding fish oil increased the concentration of ammonia and decreased total VFA, acetate, propionate, and butyrate $(P<0.05)$. Changes in total VFA, acetate, and propionate concentrations were linked to MFD severity $(P \leq 0.05)$ with the highest decreases in more responsive animals. The acetate: propionate ratio tended to be slightly lower in rumen digesta from supplemented ewes $(P=0.054)$ compared with the control, but without differences between RESPON - and RESPON+ $(P=0.73)$. Molar VFA proportions were also similar in both supplemented groups $(P>0.10)$.

\section{Bacterial Community Analysis}

The PCA of bacterial profiles (Supplemental Figure S1; https://doi.org/10.3168/jds.2018-14632) presented certain segregation by diet, with control ewes being separated from those fed the fish oil but without discrimination between RESPON- and RESPON+. Nevertheless, the first principal component accounted for only $14.5 \%$ of total variability.

Rumen bacterial T-RFLP analysis generated on average $37.9 \pm 1.42,25.0 \pm 0.99$, and $78.9 \pm 1.54$ fragments with the enzymes HhaI, MspI, and HaeIII, respectively. No treatment effect was detected on the number of T-RF (richness; Table 3), but reductions of Shannon-Wiener and Shannon evenness indices due to fish oil consumption were observed with $\mathrm{HaeIII}(P<$ $0.05)$ and $M s p I \quad(P<0.10)$ digestions. There were no significant differences in bacterial diversity linked to MFD severity.

Several T-RF relative frequencies (Supplemental Table S2; https://doi.org/10.3168/jds.2018-14632) showed irregular variations between control and MFD treatments $(P<0.10)$, with both greater (e.g., Succinivibrio-compatible 203 bp with HhaI) and lower (e.g., Clostridiales-compatible 383 bp with HhaI and 309 with HaeIII) values with the marine lipids. The abundance of most generated fragments was not different between RESPON - and RESPON+.

Table 4 shows only relative frequencies of some T-RF that varied between both supplemented groups. Fragments compatible with Prevotella spp., Quinella-related bacteria, and the genus Mogibacterium were more abundant or appeared only in ewes displaying a strong MFD, whereas the frequency of T-RF compatible with Clostridiales, Ruminococcaceae, Lachnospiraceae, or Succiniclasticum was greater in animals with a mild MFD.

\section{Principal Component Analysis}

The score plot generated from PCA of all data (i.e., ruminal fermentation parameters, $\mathrm{BH}$ metabolites, and relative frequencies of T-RF) from the adaptation period (Figure 1a) showed no a priori segregation of ewes. However, after $36 \mathrm{~d}$ on treatments (Figure 1b), control animals were clustered together and distant from the 2 groups of supplemented sheep (RESPON- and RE$\mathrm{SPON}+$ ), without separation between them.

\section{DISCUSSION}

Results from our companion study (Frutos et al., 2017), which compared changes in milk FA profile and transcript abundance of candidate genes involved in mammary lipogenesis in RESPON- versus RESPON+, did not discriminate between dairy ewes based on their responsiveness to marine lipid consumption. Neither do 
Table 1. Rumen fatty acid (FA) composition in dairy ewes fed a diet without (control) or with $2 \%$ fish oil and displaying mild (RESPON-) or strong (RESPON+) milk fat depression (data on additional FA are reported in Supplemental Table S1; https://doi.org/10.3168/jds.2018-14632)

\begin{tabular}{|c|c|c|c|c|c|c|}
\hline \multirow[b]{2}{*}{ Item } & \multicolumn{3}{|c|}{ Treatment } & \multirow[b]{2}{*}{$\mathrm{SED}^{1}$} & \multicolumn{2}{|l|}{ Contrast $^{2}$} \\
\hline & Control & RESPON- & RESPON+ & & $\begin{array}{c}\text { Control vs. } \\
(\text { RESPON }- \text { and RESPON }+)\end{array}$ & $\begin{array}{l}\text { RESPON- } \\
\text { vs. RESPON+ }\end{array}$ \\
\hline \multicolumn{7}{|l|}{ FA, g/100 g of total FA } \\
\hline $14: 0$ & 1.31 & 1.82 & 1.73 & 0.135 & 0.002 & 0.504 \\
\hline $15: 0$ & 0.87 & 0.95 & 0.81 & 0.099 & 0.800 & 0.192 \\
\hline 15:0 anteiso & 0.91 & 0.60 & 0.60 & 0.092 & 0.002 & 0.942 \\
\hline $15: 0$ iso & 0.41 & 0.37 & 0.44 & 0.032 & 0.890 & 0.068 \\
\hline trans $-5+6+7 \quad 15: 1$ & 0.39 & 0.30 & 0.34 & 0.059 & 0.207 & 0.486 \\
\hline $16: 0$ & 17.28 & 19.35 & 19.12 & 0.537 & 0.001 & 0.646 \\
\hline $16: 0$ iso & 0.38 & 0.27 & 0.28 & 0.024 & $<0.001$ & 0.494 \\
\hline cis-6+7 16:1 & 0.12 & 0.37 & 0.49 & 0.040 & $<0.001$ & 0.012 \\
\hline cis-9 16:1 & 0.10 & 0.65 & 0.77 & 0.137 & $<0.001$ & 0.384 \\
\hline trans-9 16:1 & 0.01 & 0.16 & 0.18 & 0.016 & $<0.001$ & 0.272 \\
\hline $17: 0$ & 0.66 & 0.78 & 0.75 & 0.036 & 0.005 & 0.372 \\
\hline 17:0 anteiso & 0.45 & 0.40 & 0.47 & 0.020 & 0.325 & 0.003 \\
\hline $17: 0$ iso & 0.36 & 0.57 & 0.61 & 0.045 & $<0.001$ & 0.426 \\
\hline 18:0 & 46.72 & 7.56 & 6.38 & 1.395 & $<0.001$ & 0.403 \\
\hline 9 -охо- $18: 0^{3}$ & 0.03 & 0.09 & 0.09 & 0.030 & 0.060 & 0.962 \\
\hline 10-охо-18:0 & $<0.01$ & 2.04 & 2.06 & 0.358 & $<0.001$ & 0.953 \\
\hline 15-oxo-18:0 & - & 0.02 & 0.03 & 0.006 & - & 0.217 \\
\hline cis-9 18:1 & 4.36 & 6.01 & 6.90 & 0.528 & $<0.001$ & 0.120 \\
\hline cis-11 18:1 & 0.55 & 1.72 & 1.73 & 0.127 & $<0.001$ & 0.939 \\
\hline cis-12 18:1 & 0.42 & 0.33 & 0.28 & 0.045 & 0.014 & 0.264 \\
\hline cis-13 18:1 & 0.07 & 0.16 & 0.15 & 0.014 & $<0.001$ & 0.469 \\
\hline cis-16 18:1 & 0.142 & 0.094 & 0.102 & 0.0066 & $<0.001$ & 0.246 \\
\hline$\Sigma$ cis $18: 1$ & 5.54 & 8.36 & 9.12 & 0.525 & $<0.001$ & 0.171 \\
\hline trans $-6+7+8 \quad 18: 1$ & 0.34 & 0.73 & 0.56 & 0.127 & 0.016 & 0.194 \\
\hline trans-9 18:1 & 0.24 & 0.91 & 0.91 & 0.092 & $<0.001$ & 0.929 \\
\hline trans-10 18:1 & 0.49 & 1.87 & 3.08 & 1.539 & 0.163 & 0.447 \\
\hline trans-11 18:1 & 3.11 & 20.81 & 20.85 & 1.548 & $<0.001$ & 0.981 \\
\hline trans-12 18:1 & 0.70 & 2.46 & 2.30 & 0.185 & $<0.001$ & 0.393 \\
\hline trans-13+14 18:1 & 0.95 & 1.58 & 1.49 & 0.146 & $<0.001$ & 0.564 \\
\hline trans-16 + cis-14 18:1 & 0.79 & 0.47 & 0.47 & 0.058 & $<0.001$ & 0.993 \\
\hline$\Sigma$ trans $18: 1$ & 7.06 & 29.66 & 30.52 & 1.221 & $<0.001$ & 0.499 \\
\hline cis-9,cis-12 18:2 & 6.97 & 3.32 & 3.55 & 0.503 & $<0.001$ & 0.659 \\
\hline cis-11,cis-14 18:2 & 0.050 & 0.041 & 0.049 & 0.0040 & 0.144 & 0.063 \\
\hline cis- 12, cis- $15+$ cis- 12, cis-16 $18: 2$ & - & 0.131 & 0.135 & 0.0227 & - & 0.872 \\
\hline cis-9,trans-12 18:2 & 0.02 & 0.04 & 0.04 & 0.005 & 0.002 & 0.398 \\
\hline trans-9,cis-12 18:2 & 0.04 & 0.11 & 0.11 & 0.017 & $<0.001$ & 0.803 \\
\hline trans-11, cis-15 + trans- 10, cis-15 18:2 & 0.18 & 0.80 & 0.89 & 0.079 & $<0.001$ & 0.209 \\
\hline trans-12,cis-15 + cis-11,cis-16 18:2 & 0.059 & 0.046 & 0.052 & 0.0064 & 0.092 & 0.352 \\
\hline 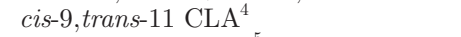 & 0.12 & 0.18 & 0.26 & 0.045 & 0.012 & 0.077 \\
\hline trans- 10, cis $^{-12} \mathrm{CLA}^{5}$ & 0.01 & 0.06 & 0.04 & 0.013 & 0.004 & 0.180 \\
\hline cis-11,trans-13 CLA & 0.041 & 0.029 & 0.021 & 0.0084 & 0.030 & 0.368 \\
\hline trans-11,trans-13 CLA & 0.025 & 0.003 & 0.002 & 0.0042 & $<0.001$ & 0.790 \\
\hline $18: 3 n-3$ & 1.48 & 0.75 & 0.79 & 0.126 & $<0.001$ & 0.763 \\
\hline trans- 9, trans- 12, cis- $1518: 3^{6}$ & 0.039 & 0.031 & 0.038 & 0.0031 & 0.107 & 0.033 \\
\hline $20: 0$ & 0.70 & 0.54 & 0.53 & 0.033 & $<0.001$ & 0.620 \\
\hline cis $-5+$ trans $-9+1020: 1$ & 0.004 & 0.070 & 0.055 & 0.0139 & $<0.001$ & 0.276 \\
\hline cis-11 + trans-15+16 20:1 & 0.18 & 0.99 & 0.97 & 0.083 & $<0.001$ & 0.776 \\
\hline $20: 4 n-3$ & $<0.01$ & 0.15 & 0.12 & 0.024 & $<0.001$ & 0.386 \\
\hline $20: 5 n-3$ & - & 0.33 & 0.33 & 0.060 & - & 0.971 \\
\hline$\Sigma$ Unsaturated C20 & 0.37 & 3.88 & 3.57 & 0.279 & $<0.001$ & 0.292 \\
\hline $22: 0^{7}$ & 0.74 & 0.60 & 0.67 & 0.044 & 0.016 & 0.146 \\
\hline cis-13 22:1 & 0.05 & 0.20 & 0.27 & 0.061 & 0.004 & 0.326 \\
\hline cis-15 22:1 & 0.025 & 0.076 & 0.123 & 0.0127 & $<0.001$ & 0.003 \\
\hline $22: 4 n-3$ & 0.032 & 0.039 & 0.127 & 0.0482 & 0.247 & 0.087 \\
\hline $22: 5 n-6$ & - & 0.86 & 0.66 & 0.209 & - & 0.367 \\
\hline $22: 5 n-3$ & - & 1.97 & 1.61 & 0.962 & - & 0.623 \\
\hline $22: 6 n-3$ & - & 0.83 & 1.27 & 0.369 & - & 0.269 \\
\hline$\Sigma$ Unsaturated C22 & 0.18 & 6.36 & 6.11 & 0.995 & $<0.001$ & 0.809 \\
\hline Total FA, g/100 $\mathrm{g}$ of digesta DM & 3.34 & 4.39 & 4.69 & 0.227 & 0.001 & 0.361 \\
\hline
\end{tabular}

${ }^{1} \mathrm{SED}=$ standard error of the difference.

${ }^{2}$ Probability of the orthogonal contrast.

${ }^{3}$ Coelutes with 10-hydroxy-18:0.

${ }^{4}$ Contains trans- 7 , cis-9 and trans-8, cis-10 CLA as minor components.

${ }^{5}$ Coelutes with a 20:2 isomer of indeterminate double-bond position.

${ }^{6}$ Coelutes with cis- 9 , cis-12,trans-15 18:3.

${ }^{7}$ Coelutes with an unidentified dimethylacetal. 
Table 2. Ruminal fermentation parameters in dairy ewes fed a diet without (control) or with $2 \%$ fish oil and displaying mild (RESPON-) or strong (RESPON+) milk fat depression

\begin{tabular}{|c|c|c|c|c|c|c|}
\hline \multirow[b]{2}{*}{ Item } & \multicolumn{3}{|c|}{ Treatment } & \multirow[b]{2}{*}{$\mathrm{SED}^{1}$} & \multicolumn{2}{|l|}{ Contrast $^{2}$} \\
\hline & Control & RESPON- & RESPON+ & & $\begin{array}{c}\text { Control vs. } \\
\text { (RESPON- and RESPON+) }\end{array}$ & $\begin{array}{l}\text { RESPON-vs. } \\
\text { RESPON+ }\end{array}$ \\
\hline $\begin{array}{l}\text { Ammonia, } \mathrm{mg} / \mathrm{L} \\
\text { VFA, mmol/L }\end{array}$ & 134.3 & 165.4 & 181.7 & 10.18 & 0.001 & 0.137 \\
\hline Total & 117.2 & 107.1 & 92.3 & 7.12 & 0.014 & 0.051 \\
\hline Acetate & 74.1 & 67.5 & 57.6 & 4.82 & 0.017 & 0.050 \\
\hline Others $^{3}$ & 4.33 & 4.00 & 3.65 & 0.445 & 0.217 & 0.450 \\
\hline Acetate:propionate ratio & 3.35 & 3.15 & 3.19 & 0.097 & 0.054 & 0.726 \\
\hline
\end{tabular}

${ }^{1} \mathrm{SED}=$ standard error of the difference.

${ }^{2}$ Probability of the orthogonal contrast.

${ }^{3}$ Calculated as the sum of isobutyrate, isovalerate, valerate, and caproate.

results from this new investigation point to a particular rumen parameter as responsible for individual variations in MFD severity.

Following the BH theory (Bauman and Griinari, 2001), our first hypothesis pointed to the formation of antilipogenic FA in the rumen. However, although fish oil supplementation increased the concentration of demonstrated or putative antilipogenic FA (such as cis9 16:1, 10-oxo-18:0, cis-11 18:1, trans-10,cis-12 CLA, or trans-10,cis-15 18:2), surprisingly, none of them differed significantly in relation to the extent of MFD (i.e., between RESPON- and RESPON+).

In general, shifts in the rumen FA profile were consistent with those observed in milk, not only for antilipogenic FA, but there were also some differences. For instance, the unexpected higher content of trans10, cis-12 CLA in the milk from RESPON- (Frutos et al., 2017) was not found in the rumen, which may be related to a coelution with 20-carbon metabolites (Toral et al., 2017) and would support a marginal role of this CLA isomer in marine lipid-induced MFD (Loor et al., 2005; Toral et al., 2012; Kairenius et al., 2015).

Differences between milk and rumen FA profiles also appeared in long-chain n-3 PUFA. The 22:6n-3 did not vary between RESPON - and RESPON+ in the rumen but did so in milk, and just the opposite occurred for $22: 4 n-3$, which tended to be greater in the rumen of more susceptible ewes. It is still uncertain whether these or other very long chain n-3 PUFA may be in the origin of MFD. However, lipogenic gene expression was inhibited in in vitro incubations of bovine mammary epithelial cells with 20:5n-3 (Kadegowda et al., 2009), and reductions in milk fat concentration after postruminal infusions of fish oil might be attributable to the combined action of these n-3 PUFA and some potentially antilipogenic FA present in fish oil, such as

Table 3. Diversity indices (richness, R; Shannon-Wiener, H; Shannon evenness, E) of rumen bacterial communities in dairy ewes fed a diet without (control) or with $2 \%$ fish oil and displaying mild (RESPON-) or strong (RESPON+) milk fat depression

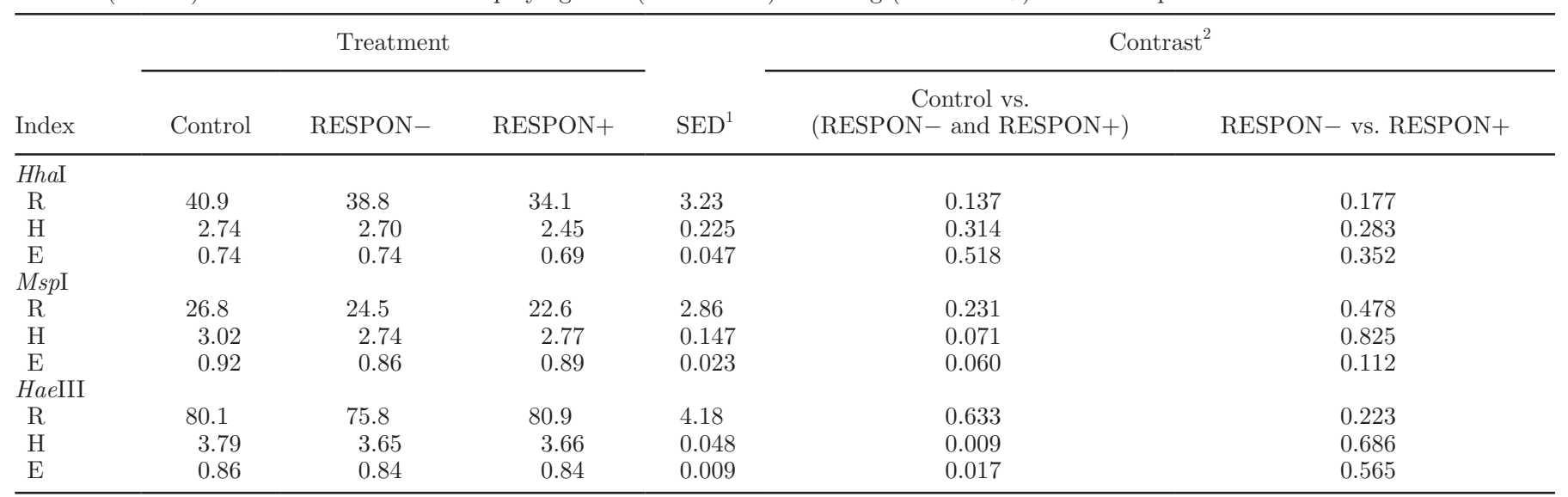

${ }^{1} \mathrm{SED}=$ standard error of the difference.

${ }^{2}$ Probability of the orthogonal contrast. 
- Control

$\triangle$ RESPON-

$\square$ RESPON+
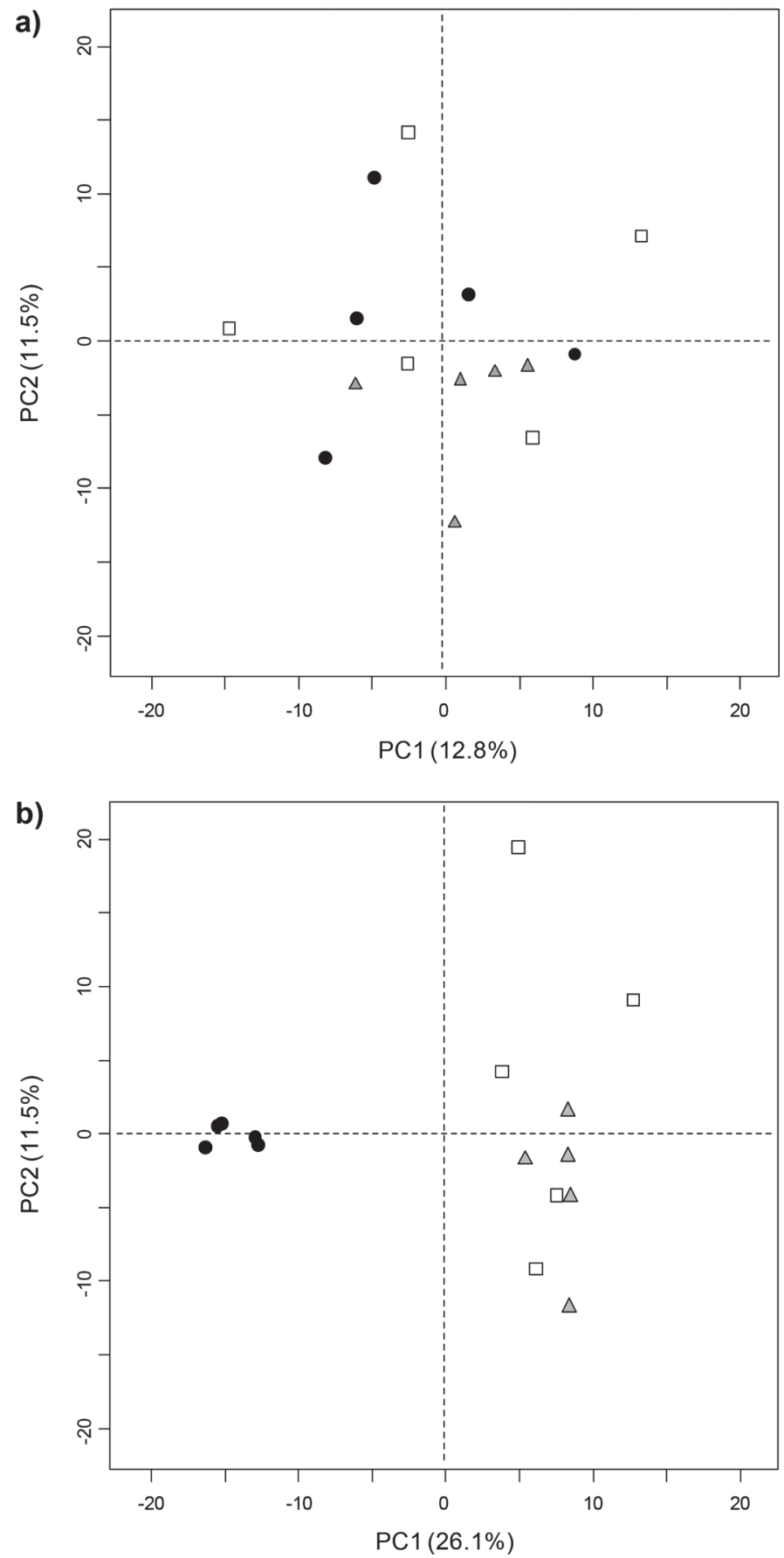

Figure 1. Principal component (PC) analysis of ruminal fermentation parameters, biohydrogenation metabolites, and relative frequencies of terminal restriction fragments in dairy ewes at the end of the adaptation period (a) and after $36 \mathrm{~d}$ (b) on a diet without (control; circles) or with $2 \%$ fish oil and displaying mild (RESPON-; triangles) or strong (RESPON+; squares) milk fat depression.

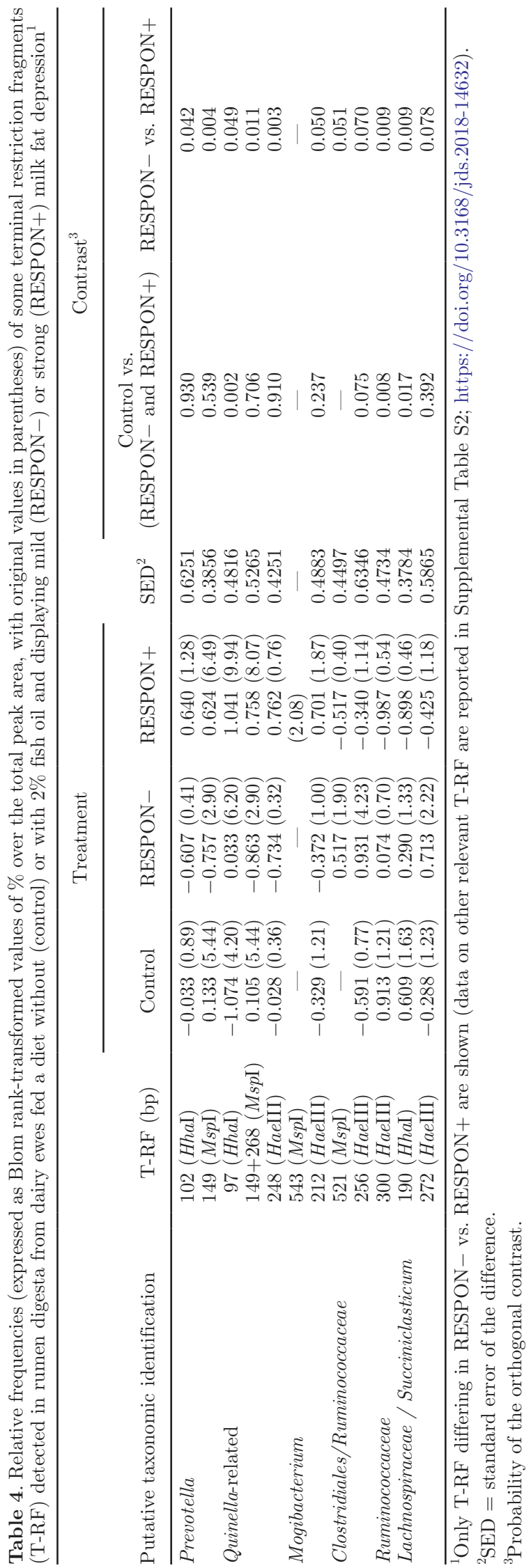


cis-9 16:1 and cis-11 18:1 (Loor et al., 2005; Burns et al., 2012; Dallaire et al., 2014).

Another metabolite of ruminal origin that has putatively been related to fish oil-induced MFD is the 10oxo-18:0, which increased with the supplemented diet but regardless of sheep responsiveness. On the other hand, differences between RESPON- and RESPON+ were found for some T-RF compatible with Quinellarelated bacteria, microorganisms reported to be favored in sheep suffering from MFD and perhaps associated with the formation of keto-acids during rumen $\mathrm{BH}$ (Toral et al., 2012).

Concerning trans-10 18:1, with an ambiguous involvement in MFD (Kadegowda et al., 2009; Shingfield et al., 2010), its changes did not reach the required level of significance because of considerable between-animal variability, something that is consistently observed (Kim et al., 2008; Or-Rashid et al., 2008; Toral et al., 2012). In our study, numerical differences between RESPON+ and RESPON - were mainly due to a very high value in a sheep displaying a strong MFD (10.4\% of total FA), which contrasts with values ranging from 1.2 to $1.4 \%$ in the other 4 ewes in RESPON+ and from 1.2 to $3.8 \%$ in animals in RESPON-. The fact that trans-10 18:1 was not related to the extent of MFD, together with its increases in dairy ewes fed plant oils and not suffering from the low-fat milk syndrome (Mele and Banni, 2010; Shingfield et al., 2010), would challenge the actual usefulness of this 18:1 isomer as an indicator of alterations in rumen BH eliciting MFD in sheep. Looking into comprehensive FA profiles may help to find better biomarkers of altered $\mathrm{BH}$, such as probably those deriving from shifts in 18:3n-3 pathways (e.g., trans-13+14 18:1 and trans-10,cis-15 18:2; Shingfield et al., 2010; Alves and Bessa, 2014). Toral et al. (2017) noticed that alterations in some of these metabolites were stronger in ovine than bovine, which may strengthen their interest as biomarkers in this small ruminant species. However, once again, most changes were independent from degrees of MFD. Only cis-11,cis-14 18:2 and trans-18:3 isomers (i.e., trans-9,trans-12,cis-15+ cis-9,cis-12,trans-15 18:3) diverged in RESPON- and RESPON+, but without significant variation when compared with the control, which precludes from relating them confidently with MFD severity. Yet, because ewes are not very prone to other MFD conditions (Mele and Banni, 2010; Shingfield et al., 2010), further research would be advisable to determine if the promotion of alternative 18:3n-3 pathways may be associated with marine lipid-induced MFD in dairy ewes.

Another metabolite showing the greatest rumen concentration in RESPON+ was cis-6+7 16:1. This agrees with observations for cis-7 16:1 in milk, where it did not coelute with cis-6 16:1 (Frutos et al., 2017). Together with cis-9 16:1, which acts as antilipogenic in ruminants (Burns et al., 2012), the cis-7 16:1 has recently attracted much attention given its anti-inflammatory activity and potential as a biomarker of proatherogenicity (Guijas et al., 2016). Some common effects by cis-9 16:1 and cis-7 16:1 might tempt speculation on certain involvement of the latter in lipid metabolism, but we are not aware of reports about this FA and ruminants or mammary lipogenesis. Something similar would occur with cis-15 22:1, a FA that comes from the fish oil and was enhanced in ewes showing severe MFD.

Differences with the extent of MFD in 15:0 iso and 17:0 anteiso were first considered to reflect changes in the rumen microbiota because of their predominant origin (i.e., bacteria leaving the rumen; Fievez et al., 2012; Buccioni et al., 2012). Thus, the increase in RESPON+ of Prevotella, a bacteria with a substantial content of 15:0 iso (Fievez et al., 2012), would be consistent with this finding. However, statistical significance was mainly due to the lower values found in RESPONcompared with the control, which does not allow us to relate them confidently to responsiveness to marine lipid consumption. The apparent inconsistency with concentrations of these FA in milk, where they did not vary for the contrast RESPON- vs. RESPON+ (Frutos et al., 2017), may be due to the postruminal modification of the odd- and branched-chain FA profile (Fievez et al., 2012).

The possible role of ruminal VFA in the development of MFD is another issue of interest: this topic seemed closed, but has recently received considerable attention. The review by Bauman and Griinari (2001) offers a reasoned argument that a deficiency in acetate could not adequately explain the reduction caused in milk fat when dairy cows are fed diets rich in concentrates or plant lipids. Under those feeding conditions, reductions in the acetate/propionate ratio are often due to increases in propionate rather than decreases in acetate production. On the other hand, marine lipids usually reduce acetate and total VFA concentrations, despite frequent increases in propionate, as observed in many in vivo and in vitro investigations with dairy cows, ewes, and goats suffering from this type of MFD (Fievez et al., 2007; AbuGhazaleh and Ishlak, 2014; Toral et al., 2016a). Recent studies have recommended reconsideration of the effect of acetate supply in milk fat synthesis and depression (Maxin et al., 2011; Urrutia and Harvatine, 2017) as it may stimulate lipogenesis further than attributable to its role as substrate for de novo FA synthesis (Jacobs et al., 2013; Urrutia and Harvatine, 2017). The differences in total VFA and acetate concentrations that we observed between ewes displaying a mild or a strong MFD were in line with the molar yields of de novo FA in milk (Frutos et al., 2017), which 
might suggest an association between them. In fact, the mild fat depression in RESPON - was explained by a lower yield of de novo FA, which would agree with the hypothesis relating the deficiency in acetate and the reduction in milk fat. Conversely, the strong MFD in RESPON+ was due to decreases not only in de novo synthesized FA but also in preformed FA deriving from plasma uptake, which would downplay the role of acetate. Thus, the milk fat fall in RESPON+ (25.4\%) was above the range of reported positive responses to ruminal infusion of this VFA (e.g., Maxin et al., 2011; Urrutia and Harvatine, 2017).

The butyrate, a VFA with uncertain relevance in milk fat synthesis (Bauman and Griinari, 2001; Maxin et al., 2011), was also reduced with fish oil. Unlike acetate and total VFA, reported changes in its concentration in response to marine lipids are very inconsistent in the literature (Fievez et al., 2007; Shingfield et al., 2012; Toral et al., 2016a). This variability might be associated with shifts in butyrate-producing microorganisms within or phylogenetically close to the Butyrivibrio group, which includes the most active biohydrogenating species isolated from the rumen (Paillard et al., 2007). In this study, however, the lack of significant differences between RESPON - and RESPON+ in butyrate does not match with variations in T-RF compatible with the family Lachnospiraceae, where those populations belong.

With respect to the concentration of ammonia, this parameter is scarcely affected by the use of marine lipids (e.g., Kim et al., 2008; Shingfield et al., 2012; Toral et al., 2016a) and we found no differences related to the severity of MFD, which was the core issue of this study.

Regarding the rumen bacterial community, the strong host-microbiota specificity in ruminants (Weimer, 2015) might contribute to explain the large individual variation in the degree of fish oil-induced MFD in sheep. In cows suffering from MFD elicited by rapidly fermented starch and monensin, animals were grouped according to bacterial structures (Weimer et al., 2010), something that did not happen in our fish oil-supplemented ewes. Yet, differences in specific bacterial populations tentatively involved in rumen $\mathrm{BH}$ might help to identify some species linked to this syndrome. For example, T-RF compatible with Mogibacterium, a genus that was enriched in cows with MFD (Pitta et al., 2018), increased or appeared only in ewes displaying a strong MFD, and the same occurred with some Prevotella and Quinella-related spp., which may also participate in rumen BH (Huws et al., 2011; Toral et al., 2012; Cremonesi et al., 2018). On the contrary, some T-RF compatible with Clostridiales, Ruminococcaceae, Lachnospiraceae, and Succiniclasticum, and associated with rumen lipid metabolism (Huws et al., 2011; Patra and
Yu, 2015; Cremonesi et al., 2018), showed greater abundances in less susceptible sheep. Therefore, it might be speculated that the latter bacteria could be favored at the expense of the former and somehow helped to minimize the extent of the low-fat milk syndrome in RESPON- ewes. In any event, it must be considered that samples collected through stomach tube contain mostly liquid, which requires caution when using this technique to assess the structure and diversity of the rumen microbial community (Ramos-Morales et al., 2014). Although the technique has been used in lipid metabolism studies (e.g., Or-Rashid et al., 2008; Toral et al., 2016a; Cremonesi et al., 2018), perhaps further differences between RESPON - and RESPON+ could be detected if the whole rumen content (liquid plus solid fractions) was analyzed.

Finally, although it cannot be ruled out that the individual variation in MFD severity could be due to the existence of underlying differences in the ruminal environment, the results from the PCA (see Figure 1) suggest that there was no evident previous condition predisposing the response of ewes to fish oil consumption. At the end of the experimental period, this analysis was able to discriminate clearly between control and low milk fat animals but not between dairy ewes displaying mild or strong MFD, which is in line with the small number of parameters differing significantly in RESPON- and RESPON+.

Overall, the results support that fish oil-induced MFD is most probably a multi-etiological syndrome with several causal factors (i.e., antilipogenic FA coming from the fish oil, rumen metabolites formed in the $\mathrm{BH}$ process, promotion or reduction of specific rumen bacteria, deficiency of acetate, and so on). Postruminal factors, particularly those acting at the mammary gland (e.g., milk FA composition or mammary transcriptome; Shingfield et al., 2010; Suárez-Vega et al., 2017), must be added to the list. All together, they could explain the gradual nature of the response, as different sensitivity of each animal to each particular factor would come into play.

\section{CONCLUSIONS}

Individual variation in the extent of MFD in ewes fed fish oil cannot be fully explained by the processes of rumen $\mathrm{BH}$ and fermentation or the bacterial community. Surprisingly, none of the demonstrated or putative antilipogenic FA varied significantly between ewes displaying different degrees of MFD (i.e., between RESPON - and RESPON+), and this was the case only for a few minor FA (e.g., cis- $6+7$ 16:1 or 17:0 anteiso). Changes in total VFA, acetate, and propionate concentrations were associated with MFD severity, 
with higher decreases in more susceptible animals. Individual variability in responsiveness was not related to rumen bacterial structure but some T-RF compatible with Clostridiales, Ruminococcaceae, Lachnospiraceae, and Succiniclasticum showed greater abundances in RESPON-, whereas some others that may correspond to Prevotella, Mogibacterium, and Quinella-related spp. were more abundant in RESPON+. Overall, the results support that fish oil-induced MFD would be a multietiological condition with several causal factors, and further research is still necessary to explain individual variation in the extent of this syndrome.

\section{ACKNOWLEDGMENTS}

This study was supported by the Spanish Ministry of Economy and Competitiveness (MINECO; AGL201454587-R) and the European Regional Development Fund. The authors thank A. G. Mendoza [Instituto de Ganadería de Montaña (IGM), León, Spain] for his help with FA analysis and experimental animals. L. Rodríguez's (IGM) help during the in vivo assay is also acknowledged. P. G. Toral benefits from a Ramón y Cajal research contract from the MINECO.

\section{REFERENCES}

Abdo, Z., U. M. E. Schüette, S. J. Bent, C. J. Williams, L. J. Forney, and P. Joyce. 2006. Statistical methods for characterizing diversity of microbial communities by analysis of terminal restriction fragment length polymorphisms of $16 \mathrm{~S}$ rRNA genes. Environ. Microbiol. 8:929-938.

AbuGhazaleh, A. A., and A. Ishlak. 2014. Effects of incremental amounts of fish oil on trans fatty acids and Butyrivibrio bacteria in continuous culture fermenters. J. Anim. Physiol. Anim. Nutr. (Berl.) 98:271-278.

Alves, S. P., and R. J. B. Bessa. 2014. The trans-10,cis-15 18:2: A missing intermediate of trans-10 shifted rumen biohydrogenation pathway? Lipids 49:527-541.

Bauman, D. E., and J. M. Griinari. 2001. Regulation and nutritional manipulation of milk fat: Low-fat milk syndrome. Livest. Prod. Sci. 70:15-29.

BOE (Boletín Oficial del Estado). 2013. Royal Decree 53/2013, of 8 February, on the protection of animals used for experimental purposes. Pages 11370-11421 in Boletín Oficial del Estado. Spanish Government Publishing, Madrid, Spain.

Buccioni, A., M. Decandia, S. Minieri, G. Molle, and A. Cabiddu. 2012. Lipid metabolism in the rumen: New insights on lipolysis and biohydrogenation with an emphasis on the role of endogenous plant factors. Anim. Feed Sci. Technol. 174:1-25.

Burns, T. A., A. K. G. Kadegowda, S. K. Duckett, S. L. Pratt, and T. C. Jenkins. 2012. Palmitoleic (16:1 cis-9) and cis-vaccenic (18:1 cis-11) acid alter lipogenesis in bovine adipocyte cultures. Lipids 47:1143-1153.

Cremonesi, P., G. Conte, M. Severgnini, F. Turri, A. Monni, E. Capra, L. Rapetti, S. Colombini, S. Chessa, G. Battelli, S. P. Alves, M. Mele, and B. Castiglioni. 2018. Evaluation of the effects of different diets on microbiome diversity and fatty acid composition of rumen liquor in dairy goat. Animal https://doi.org/10.1017/ S1751731117003433.

Dallaire, M. P., H. Taga, L. Ma, B. A. Corl, R. Gervais, Y. Lebeuf, F. J. Richard, and P. Y. Chouinard. 2014. Effects of abomasal infusion of conjugated linoleic acids, Sterculia foetida oil, and fish oil on production performance and the extent of fatty acid $\Delta^{9}$ desaturation in dairy cows. J. Dairy Sci. 97:6411-6425.

Enjalbert, F., S. Combes, A. Zened, and A. Meynadier. 2017. Rumen microbiota and dietary fat: A mutual shaping. J. Appl. Microbiol. 123:782-797.

EU (European Union). 2010. Directive 2010/63/EU of the European Parliament and of the Council of 22 September 2010 on the protection of animals used for scientific purposes. Off. J. Eur. Union 276:33-79.

Fievez, V., C. Boeckaert, B. Vlaeminck, J. Mestdagh, and D. Demeyer. 2007. In vitro examination of DHA-edible micro-algae 2. Effect on rumen methane production and apparent degradability of hay. Anim. Feed Sci. Technol. 136:80-95.

Fievez, V., E. Colman, J. M. Castro-Montoya, I. Stefanov, and B. Vlaeminck. 2012. Milk odd- and branched-chain fatty acids as biomarkers of rumen function-An update. Anim. Feed Sci. Technol. 172:51-65.

Frutos, P., P. G. Toral, and G. Hervás. 2017. Individual variation of the extent of milk fat depression in dairy ewes fed fish oil: milk fatty acid profile and mRNA abundance of candidate genes involved in mammary lipogenesis. J. Dairy Sci. 100:9611-9622.

Guijas, C., C. Meana, A. M. Astudillo, M. A. Balboa, and J. Balsinde. 2016. Foamy monocytes are enriched in cis-7-hexadecenoic fatty acid (16:1n-9), a possible biomarker for early detection of cardiovascular disease. Cell Chem. Biol. 23:689-699.

Hill, T. C. J., K. A. Walsh, J. A. Harris, and B. F. Moffett. 2003. Using ecological diversity measures with bacterial communities. FEMS Microbiol. Ecol. 43:1-11.

Hongoh, Y., H. Yuzawa, M. Ohkuma, and T. Kudo. 2003. Evaluation of primers and PCR conditions for the analysis of $16 \mathrm{~S}$ rRNA genes from a natural environment. FEMS Microbiol. Lett. 221:299-304.

Huws, S. A., E. J. Kim, M. R. F. Lee, M. B. Scott, J. K. S. Tweed, E. Pinloche, R. J. Wallace, and N. D. Scollan. 2011. As yet uncultured bacteria phylogenetically classified as Prevotella, Lachnospiraceae incertae sedis and unclassified Bacteroidales, Clostridiales and Ruminococcaceae may play a predominant role in ruminal biohydrogenation. Environ. Microbiol. 13:1500-1512.

Jacobs, A. A. A., J. Dijkstra, J. S. Liesman, M. J. VandeHaar, A. L. Lock, A. M. van Vuuren, W. H. Hendriks, and J. van Baal. 2013. Effects of short- and long-chain fatty acids on the expression of stearoyl-CoA desaturase and other lipogenic genes in bovine mammary epithelial cells. Animal 7:1508-1516.

Kadegowda, A. K. G., M. Bionaz, L. S. Piperova, R. A. Erdman, and J. J. Loor. 2009. Peroxisome proliferator-activated receptorgamma activation and long-chain fatty acids alter lipogenic gene networks in bovine mammary epithelial cells to various extents. J. Dairy Sci. 92:4276-4289.

Kairenius, P., A. Ärölä, H. Leskinen, V. Toivonen, S. Ahvenjärvi, A Vanhatalo, P. Huhtanen, T. Hurme, J. M. Griinari, and K. J. Shingfield. 2015. Dietary fish oil supplements depress milk fat yield and alter milk fatty acid composition in lactating cows fed grass silage based diets. J. Dairy Sci. 98:5653-5671.

Kim, E. J., S. A. Huws, M. R. F. Lee, J. D. Wood, S. M. Muetzel, R. J. Wallace, and N. D. Scollan. 2008. Fish oil increases the duodenal flow of long chain polyunsaturated fatty acids and trans-11 18:1 and decreases 18:0 in steers via changes in the rumen bacterial community. J. Nutr. 138:889-896.

Loor, J. J., M. Doreau, J. M. Chardigny, A. Ollier, J. L. Sebedio, and Y. Chilliard. 2005. Effects of ruminal or duodenal supply of fish oil on milk fat secretion and profiles of trans-fatty acids and conjugated linoleic acid isomers in dairy cows fed maize silage. Anim. Feed Sci. Technol. 119:227-246.

Lourenço, M., E. Ramos-Morales, and R. J. Wallace. 2010. The role of microbes in rumen lipolysis and biohydrogenation and their manipulation. Animal 4:1008-1023.

Maxin, G., H. Rulquin, and F. Glasser. 2011. Response of milk fat concentration and yield to nutrient supply in dairy cows. Animal 5:1299-1310.

Mele, M., and S. Banni. 2010. Lipid supplementation in small ruminant nutrition and dairy products quality: implications for human nutrition. M. Crovetto, ed. Energy and Protein Metabolism and 
Nutrition EAAP Publications n. 127, Wageningen Pers, Wageningen, the Netherlands.

Or-Rashid, M. M., J. K. G. Kramer, M. A. Wood, and B. W. McBride. 2008. Supplemental algal meal alters the ruminal trans-18:1 fatty acid and conjugated linoleic acid composition in cattle. J. Anim. Sci. 86:187-196.

Ottenstein, E. R., and D. A. Bartley. 1971. Separation of free acids C2-C5 in dilute aqueous solution column technology. J. Chromatogr. Sci. 9:673-681.

Paillard, D., N. McKain, L. C. Chaudhary, N. D. Walker, F. Pizette, I. Koppova, N. R. McEwan, J. Kopecny, P. E. Vercoe, P. Louis, and R. J. Wallace. 2007. Relation between phylogenetic position, lipid metabolism and butyrate production by different Butyrivibrio-like bacteria from the rumen. Antonie Van Leeuwenhoek 91:417-422.

Palmquist, D. L., and T. C. Jenkins. 2017. A 100-year review: Fat feeding of dairy cows. J. Dairy Sci. 100:10061-10077.

Patra, A. K., and Z. Yu. 2015. Essential oils affect populations of some rumen bacteria in vitro revealed by microarray (RumenBactArray) analysis. Front. Microbiol. 6:297.

Pitta, D. W., N. Indugu, B. Vechiarelli, D. E. Rico, and K. J. Harvatine. 2018. Alterations in ruminal bacterial populations at induction and recovery from diet-induced milk fat depression in dairy cows. J. Dairy Sci. 101:295-309.

Ramos-Morales, E., A. Arco-Pérez, A. I. Martín-García, D. R. YáñezRuiz, P. Frutos, and G. Hervás. 2014. Use of stomach tubing as an alternative to rumen cannulation to study ruminal fermentation and microbiota in sheep and goats. Anim. Feed Sci. Technol. 198:57-66.

Reardon, J., J. A. Foreman, and R. L. Searcy. 1966. New reactants for colorimetric determination of ammonia. Clin. Chim. Acta 14:203-205.

Reynolds, C. K., V. L. Cannon, and S. C. Loerch. 2006. Effects of forage source and supplementation with soybean and marine algal oil on milk fatty acid composition of ewes. Anim. Feed Sci. Technol. 131:333-357.

Shingfield, K. J., S. Ahvenjärvi, V. Toivonen, A. Äröla, K. V. V. Nurmela, P. Huhtanen, and J. M. Griinari. 2003. Effect of dietary fish oil on biohydrogenation of fatty acids and milk fatty acid content in cows. Anim. Sci. 77:165-179.

Shingfield, K. J., L. Bernard, C. Leroux, and Y. Chilliard. 2010. Role of trans fatty acids in the nutritional regulation of mammary lipogenesis in ruminants. Animal 4:1140-1166.
Shingfield, K. J., P. Kairenius, A. Äröla, D. Paillard, S. Muetzel, S. Ahvenjärvi, A. Vanhatalo, P. Huhtanen, V. Toivonen, J. M. Griinari, and R. J. Wallace. 2012. Dietary fish oil supplements modify ruminal biohydrogenation, alter the flow of fatty acids at the omasum, and induce changes in the ruminal Butyrivibrio population in lactating cows. J. Nutr. 142:1437-1448.

Suárez-Vega, A., P. G. Toral, B. Gutiérrez-Gil, G. Hervás, J. J. Arranz, and P. Frutos. 2017. Elucidating fish oil-induced milk fat depression in dairy sheep: Milk somatic cell transcriptome analysis. Sci. Rep. 7:45905.

Toral, P. G.. A. Belenguer, K. J. Shingfield, G. Hervás, V. Toivonen, and P. Frutos. 2012. Fatty acid composition and bacterial community changes in the rumen fluid of lactating sheep fed sunflower oil plus incremental levels of marine algae. J. Dairy Sci. 95:794-806.

Toral, P. G., L. Bernard, A. Belenguer, J. Rouel, G. Hervás, Y. Chilliard, and P. Frutos. 2016a. Comparison of ruminal lipid metabolism in dairy cows and goats fed diets supplemented with starch, plant oil, or fish oil. J. Dairy Sci. 99:301-316.

Toral, P. G., G. Hervás, D. Carreño, and P. Frutos. 2016b. Does supplemental 18:0 alleviate fish oil-induced milk fat depression in dairy ewes? J. Dairy Sci. 99:1133-1144.

Toral, P. G., G. Hervás, D. Carreño, H. Leskinen, A. Belenguer, K. J. Shingfield, and P. Frutos. 2017. In vitro response to EPA, DPA, and DHA: Comparison of effects on ruminal fermentation and biohydrogenation of 18-carbon fatty acids in cows and ewes. J. Dairy Sci. 100:6187-6198.

Urrutia, N. L., and K. J. Harvatine. 2017. Acetate dose-dependent stimulates milk fat synthesis in lactating dairy cows. J. Nutr. 147:763-769.

Weimer, P. J. 2015. Redundancy, resilience, and host specificity of the ruminal microbiota: Implications for engineering improved ruminal fermentations. Front. Microbiol. 6:296.

Weimer, P. J., D. M. Stevenson, and D. R. Mertens. 2010. Shifts in bacterial community composition in the rumen of lactating dairy cows under milk fat-depressing conditions. J. Dairy Sci. 93:265278.

Yu, Z., and M. Morrison. 2004. Improved extraction of PCR-quality community DNA from digesta and fecal samples. Biotechniques $36: 808-812$. 